LETTERS

\title{
Secondary addition of methotrexate to partial responders to etanercept alone is effective in severe rheumatoid arthritis
}

\author{
J D Cohen, S Zalłni, M J Kaiser, M C Bozonnat, C Jorgensen, J P Daurès, J Sany
}

Ann Rheum Dis 2004;63:209-210. doi: 10.1136/ard.2003.013532

$\mathrm{E}$ tanercept, a soluble tumour necrosis factor $\alpha(\mathrm{TNF} \alpha)$ receptor fusion protein, may be combined with methotrexate (MTX) in severe rheumatoid arthritis (RA). ${ }^{1}$ Etanercept is generally given to patients treated with MTX who have an inadequate response. However, MTX could be introduced to patients who have already been treated with etanercept and who initially had a good response but subsequently a secondary failure. It was decided to evaluate, in an open prospective study, the clinical, biological, and functional benefit of the secondary addition of MTX in patients with RA with an inadequate response to etanercept alone.

\section{PATIENTS, METHODS, AND RESULTS}

A cohort of 93 patients with active and severe RA was observed for a mean duration of 8 months (range 1-20). The group comprised 75 women, 18 men, with an average age of 49.5 years (range 17-75), and positive rheumatoid factor in $67(72 \%)$. All had been previously treated with a median of four disease modifying antirheumatic drugs (DMARDs). The mean disease duration was 12.4 years (range 3-42). Patients were treated with subcutaneous injections of etanercept alone, $25 \mathrm{mg}$ twice weekly. Eighteen of the 93 patients had an inadequate response (did not reach the American College of Rheumatology (ACR) 20 criteria, prerequisite for inclusion in this cohort) with etanercept alone; we therefore added MTX to the treatment, no other DMARDs being allowed. The mean dose of added MTX was $15.5 \mathrm{mg}$ a week. The dosage was given orally to 12 patients and intramuscularly to the remaining six. All 18 patients ( 16 female, two male, average age 51 years, mean disease duration 13.3 years, with a positive rheumatoid factor in 14 (78\%) patients) had previously received MTX before etanercept alone, but it had produced an insufficient result. This failure with MTX was a requirement before starting etanercept. A prospective follow up of these patients took place every month for 3 months and from then on every 3 months during a 12 month period, with recording of the usual clinical and biological measures in order to obtain the ACR20, 50, and 70 and the Disease

Activity Score 28 (DAS28). This enabled us to assess the efficacy of this addition. The Health Assessment Questionnaire (HAQ) was also used in this study.

Table 1 summarises the results obtained. The data show an improvement in disease activity, which was sustained through the 12 month follow up. A favourable response was obtained at 3 months with $10(56 \%)$ achieving the ACR20, $5(28 \%)$ the ACR50, and $2(11 \%)$ the ACR70. At 12 months of this combination therapy, 12 (67\%) had achieved the ACR20, $9(50 \%)$ the ACR50, and $3(17 \%)$ the ACR70. DAS28 decreased from 4.9 to 3.0 at 3 months and to 2.4 at 1 year, suggesting a significant clinical improvement in disability. The HAQ score changed from 1.7 to 1.1 at 1 year.

There was also a rapid therapeutic biological response, with a decrease in the erythrocyte sedimentation rate (ESR) and C reactive protein (CRP) of $50 \%$ after 3 months. No serious adverse events were reported and only two patients required antibiotics (bronchitis, urinary infection).

\section{DISCUSSION}

In summary, this open study suggests that the secondary addition of MTX to etanercept produced a marked improvement among patients who had had an inadequate response to etanercept alone after a first inadequate response to MTX given alone. To our knowledge, this is the first open study to evaluate the efficacy of MTX in addition to etanercept in a two step strategy. Previous studies have demonstrated the efficacy of etanercept alone compared with $\mathrm{MTX}^{2}$ its efficacy in early $\mathrm{RA}^{3}$ or in addition to methotrexate, ${ }^{1}$ and, in particular, in juvenile idiopathic arthritis. ${ }^{4}$ This suggests that when MTX is added to the etanercept regimen patients with RA improve both clinically and biologically without any increase in side effects. The addition of MTX to the treatment of patients who respond incompletely to etanercept alone may be useful in the management of RA. It will be interesting to evaluate this strategy in further studies. Therefore, the preferred treatment

Table 1 Results of secondary addition of MTX to etanercept

\begin{tabular}{lllllll}
\hline \multicolumn{7}{c}{ MTX duration (months) } \\
\cline { 2 - 7 } & $\mathbf{0}$ & $\mathbf{3}$ & $\mathbf{6}$ & $\mathbf{9}$ & $\mathbf{1 2}$ & Friedman; $\mathrm{p}$ value \\
\hline ACR20 (\%) & & 56 & 61 & 67 & 67 & \\
ACR50 (\%) & 28 & 28 & 39 & 50 & \\
ACR70 (\%) & & 11 & 6 & & 17 & \\
DAS28, mean & 4.9 & 3.0 & 2.9 & 2.8 & 2.4 & 0.0017 \\
Score HAQ, mean & 1.7 & 1.3 & 1.2 & 1.2 & 1.1 & 0.0081 \\
ESR (mm//st h), mean & 49.1 & 33.2 & 30.6 & 33.8 & 27.2 & 0.1266 \\
CRP (mg/l), mean & 56.6 & 24.0 & 13.8 & 17.1 & 12.3 & 0.0001 \\
\hline
\end{tabular}


for RA may very well be the combination of MTX plus a TNF antagonist.

\section{Authors' affiliations \\ J D Cohen, S Zaltni, M J Kaiser, C Jorgensen, J Sany, Service d'Immuno-Rhumatologie, Hôpital Lapeyronie, Montpellier, France M C Bozonnat, J P Daurès, Institut Universitaire de Recherche Clinique, Montpellier, France}

Correspondence to: Dr J D Cohen, Immunorheumatology, CHU Lapeyronie,371 avenue du Doyen Gaston Giraud, 34295 Montpellier, Cedex 5, France; id-cohen@chu-montpellier.fr

Accepted 28 September 2003

\section{REFERENCES}

1 Weinblatt ME, Kremer JM, Bankhurst AD, Bulpitt KJ, Fleischmann RM, Fox RI, et al. A trial of etanercept, a recombinant tumor necrosis factor receptor: $\mathrm{Fc}$ fusion protein in patients with rheumatoid arthritis receiving methotrexate. N Engl J Med 1999;340:253-9.

2 Moreland LW, Schiff MH, Baumgartner SW, Tindall EA, Fleischmann RM, Bulpitt KJ, et al. Etanercept therapy in rheumatoid arthritis. A randomized, controlled trial. Ann Intern Med 1999:130:478-86.

3 Genovese MC, Bathon JM, Martin RW, Fleischmann RM, Tesser JR, Schiff MH, et al. Etanercept versus methotrexate in patients with early rheumatoid arthritis: two-year radiographic and clinical outcomes. Arthritis Rheum 2002:46:1443-50

4 Schmeling H, Mathony K, John V, Keyber G, Burdach ST, Horneff G. A combination of etanercept and methotrexate for the treatment of refractory juvenile idiopathic arthritis: a pilot study. Ann Rheum Dis $2001 ; 60: 410-12$

\section{Blunted coronary flow reserve in systemic sclerosis: a sign of cardiac involvement in asymptomatic patients}

\section{A Sulli, M Ghio, G P Bezante, L Deferrari, C Craviotto, V Sebastiani, M Setti, G Filaci, F Puppo, A Barsotti, M Cutolo, F Indiveri}

C ardiac disease is often present in systemic sclerosis (SSc), even if rarely of clinical significance. ${ }^{1-3}$ Therefore, we investigated the coronary flow reserve (CFR), by transthoracic contrast enhanced second harmonic Doppler echocardiography, a non-invasive method that might detect early heart dysfunction in patients with SSc even in the absence of clinical signs or symptoms.

Twenty nine consecutive patients ( 2 male, 27 female, mean (SD) age 55 (14) years) affected by SSc, ${ }^{45}$ not complaining of signs or symptoms of cardiovascular involvement, were recruited. No further serious disease other than SSc was present. Eleven healthy subjects matched for age and sex (mean (SD) age 53 (5) years) were also evaluated as controls. Echocardiography was performed with an ultrasound unit using a broadband transducer with second harmonic capability in both B mode and Doppler modality. Levovist was used as the ultrasound contrast agent. ${ }^{67}$ The CFR, expressed as the ratio between hyperaemic (peak adenosine infusion) and resting, both peak, diastolic velocity (PdvCFR) and velocity time integral (VtiCFR), was non-invasively assessed in the distal left anterior descending coronary. Peripheral microangiopathy was assessed by nailfold videocapillaroscopy (NVC), as previously reported. ${ }^{8}$

All patients were found in sinus rhythm, without any significant ECG alteration. All ECG parameters were normal.

The study showed a reduced CFR in 14/29 patients with SSc, when compared with the normal range of healthy subjects matched for age and sex $\left(\right.$ CFR > 2.00). ${ }^{7}$ In particular, both PdvCFR and VtiCFR, were strongly reduced in patients with SSc (mean (SD) 1.93 (0.56) and 1.81 (0.56), respectively) in comparison with controls (3.11 (0.72) and $2.83(0.51)$, respectively) $(\mathrm{p}<0.0001)$. Furthermore, both PdvCFR and VtiCFR were significantly lower in patients with diffuse SSc (1.74 (0.46) and $1.59(0.38)$, respectively) than in patients with limited SSc $(2.39(0.52)$ and 2.35 (0.38), respectively) $(\mathrm{p}<0.004$ and $\mathrm{p}<0.001$, respectively) (fig 1).

Nineteen patients (mean (SD) age 52 (13) years) and 10 patients (mean (SD) age 63 (12) years) had diffuse SSc (dSSc) and limited SSc (ISSc), respectively; the patients with dSSc were younger than those with ISSc $(\mathrm{p}<0.04)$.
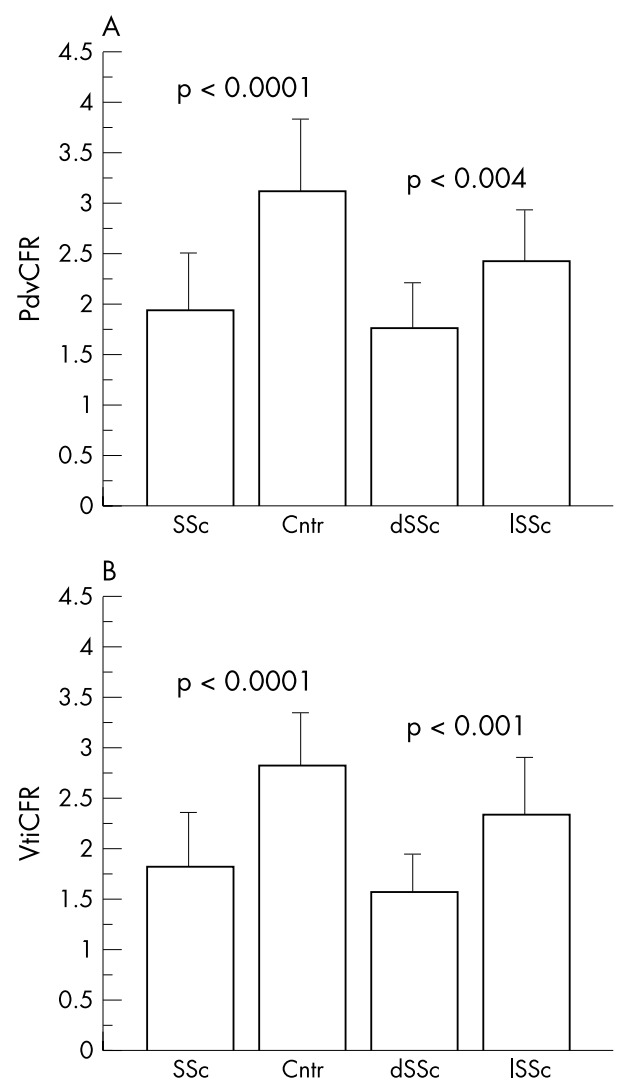

Figure 1 CFR in patients with SSc and controls (Cntr), assessed by transthoracic contrast enhanced second harmonic Doppler and expressed as the ratio between hyperaemic and resting, both peak, diastolic velocity (PdvCFR) (A) and velocity time integral (VtiCFR) (B). dSSc, patients with diffuse SSc; ISSc, patients with limited SSc.

Glucose serum levels were normal in all patients with SSc. No statistically significant correlation was found between CFR and history of smoking and cholesterol or triglyceride serum levels. Moreover, no statistically significant correlation was found between CFR and blood pressure values. 
No statistically significant correlation was found between CFR and the age of the patients, duration of SSc, or the presence of antinuclear antibodies, anticentromere antibodies, and Scl-70

No statistically significant CFR difference was found between patients with different degrees of peripheral microangiopathy ("early", "active", and "late" scleroderma pattern, as assessed by NVC).

Therefore, this study showed that patients with SSc may have clinically asymptomatic heart function impairment. In particular, the CFR values detected were significantly lower in patients with dSSc than in patients with ISSc. Patients with dSSc were younger than those with ISSc, indicating that the age of the patients is not important in the development of scleroderma heart disease. Patients with ISSc often develop clinical manifestations that are different or less severe than those of patients with dSSc, and the lower CFR found in patients with dSSc seems to support to this observation. Therefore, the present results confirm previous studies showing that patients with dSSc often have cardiac disease. ${ }^{9} 10$

In conclusion, CFR evaluation is an efficient, non-invasive, and reliable tool for assessing early cardiac disease in SSc. A reduced CFR value should be considered an indirect sign of SSc heart involvement, even if its clinical and prognostic significance needs to be further clarified.

\section{Authors' affiliations}

A Sulli, C Craviotto, M Cutolo, Division of Rheumatology, Department of Internal Medicine, University of Genova, Genova, Italy

G P Bezante, L Deferrari, V Sebastiani, A Barsotti, Division of Cardiology, Department of Internal Medicine, University of Genova, Genova, Italy
M Ghio, M Setti, G Filaci, F Puppo, F Indiveri, Division of Immunology and Internal Medicine, Department of Internal Medicine, University of Genova, Genova, Italy

Correspondence to: Dr A Sulli, Research Laboratory and Division of Rheumatology, Department of Internal Medicine, University of Genova, Viale Benedetto XV No 6, 16132 Genova, Italy; albertosulli@unige.it

Accepted 21 May 2003

\section{REFERENCES}

1 Hesselstrand R, Scheja A, Akesson A. Mortality and causes of death in a Swedish series of systemic sclerosis patients. Ann Rheum Dis 1998;57:682-6.

2 Follansbee WP. The cardiovascular manifestations of systemic sclerosis (scleroderma). Curr Probl Cardiol 1986;11:241-98.

3 Valentini G, Vitale DF, Giunta A, Maione S, Gerundo G, Arnese M, et al Diastolic abnormalities in systemic sclerosis: evidence for associated defective cardiac functional reserve. Ann Rheum Dis 1996;55:455-60.

4 LeRoy EC, Medsger TA Jr. Criteria for the classification of early systemic sclerosis. J Rheumatol $2001 ; 28: 1573-6$.

5 LeRoy EC, Black CM, Fleischmajer R, Jablonska S, Krieg T, Medsger TA, et al. Scleroderma (systemic sclerosis); classification, subsets and pathogenesis. J Rheumatol 1988;15:202-5.

6 Pizzuto F, Voci P, Mariano E, Puddu PE, Sardella G, Nigri A. Assessment of flow velocity reserve by transthoracic Doppler echocardiography and venous adenosine infusion before and after left anterior descending coronary artery stenting. J Am Coll Cardiol 2001;38:155-62.

7 Caiati C, Montaldo C, Zedda N, Bina A, lliceto S. New non invasive method for coronary flow reserve assessment: contrast enhanced transthoracic second harmonic echo Doppler. Circulation 1999;99:771-8.

8 Cutolo M, Sulli A, Pizzorni C, Accardo S. Nailfold videocapillaroscopy assessment of microvascular damage in systemic sclerosis. J Rheumatol 2000;27:155-60.

9 Weiner ES, Earnshaw WC, Senecal JL, Bordwell B, Johnson P, Rothfield NF. Clinical associations of anticentromere antibodies and antibodies to topoisomerase I. A study of 355 patients. Arthritis Rheum 1988;31:378-85.

10 Maricq HR, Harper FE, Khan MM, Tan EM, LeRoy EC. Microvascular abnormalities as possible predictors of disease subset in Raynaud's phenomenon and early connective tissue disease. Clin Exp Rheumatol 1983;1:195-205.

\title{
Incidentally discovered asymptomatic necrotising intra- abdominal vasculitis after peripheral gastric bypass surgery for morbid obesity
}

\author{
A Bounas, M Melachrinou, G Giannopoulos, N Meimaris, P Aroukatos, F Kalfarentzos, \\ A P Andonopoulos
}

W describe the case of a 35 year old woman, who underwent peripheral gastric bypass type Roux-Y surgery for morbid obesity, and was incidentally discovered to have diffuse abdominal necrotising vasculitis, which has remained silent for at least 15 months.

\section{CASE REPORT}

The patient was referred to us because a biopsy of the appendix removed at surgery had disclosed necrotising vasculitis (fig 1), and her serology had shown positive antinuclear antibodies (ANA), 1/320 homogeneous. She had received bronchodilators in the past, amoxicillin clavulanate, oral contraceptives, and fenfluramine for a short time. No recent vaccination had been administered. She denied systemic symptoms, arthralgias or arthritis, skin or mucosal lesions, abdominal pain or rectal bleeding, sicca symptoms, or Raynaud's phenomenon. After surgery she had lost $45 \mathrm{~kg}$ and, as expected, she had been experiencing mild abdominal cramps and diarrhoea shortly after meals. Physical examination was normal.
Routine laboratory investigations, including haematology, biochemistry, and urine analysis, chest $x$ ray examination, and a purified protein derivative skin test were normal. Besides the positive ANA, complete serology, including antineutrophil cytoplasmic antibodies perinuclear and cytoplasmic, antiproteinase 3, and anti-myeloperoxidase antibodies, and tests for hepatitis B and C virus, was unrevealing. Abdominal and cardiac ultrasound, mammography, and PAP test were normal.

A biopsy of skin and muscle of the gastrocnemia did not show abnormalities. An abdominal multislice computed tomography-angiography was consistent with vasculitis of the polyarteritis nodosa (PAN) type, showing bead-like, concentric stenoses and dilatations of multiple branches of the superior mesenteric artery (fig 2 ).

The diagnosis of a medium and small, muscular-type, necrotising arteritis was made, albeit silent, and the patient followed up closely. Today, 15 months after surgery, she has remained clinically asymptomatic, without laboratory abnormalities, enjoying a normal life and approaching the ideal body weight. 


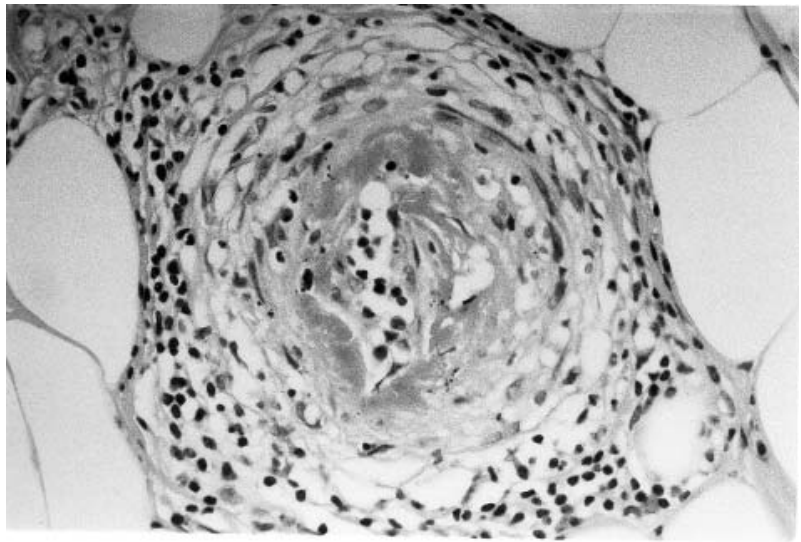

Figure 1 Small artery of the appendiceal wall, showing fibrinoid necrosis of the intima, and inflammatory infiltrate, consisting predominantly of lymphocytes in and around the vessel wall (haematoxylin and eosin $\times 400$, original magnification).

\section{DISCUSSION}

Vasculitis of the PAN type, localised to the appendix or the gall bladder, has been accidentally found, usually after surgery. ${ }^{1}$ Its prognosis is almost always good, in contrast with vasculitis that is found when systemic PAN has already been diagnosed. ${ }^{1}$ Several possibilities can be suggested for the aetiology of the diffuse intra-abdominal vasculitis of our patient. Firstly, a relationship with the operation can be easily excluded because the disease was already present in the appendix before the procedure.

A second possibility may implicate the morbid obesity of the patient. Intra-abdominal processes such as pancreatitis and malignancy, but other systemic diseases also, such as infectious endocarditis, atrial myxoma, and drug abuse, have been reported to mimic the visceral angiographic appearance of vasculitis. ${ }^{2}$ No such problems were present, and furthermore, morbid obesity has never been reported to cause vasculitis.

The positive ANA may suggest systemic lupus erythematosus as a third possibility, but our patient had no other evidence to support this diagnosis.

Drug induced vasculitis may be a fourth possibility. ${ }^{3-6}$ In the vast majority of cases it affects the skin, but it may extend to internal organs. The diagnosis is usually one of exclusion and a timely relationship to the offending drug should be documented. Almost any drug can be blamed. However, it is rather unlikely that one of the drugs the patient had taken would have induced abdominal vasculitis, without skin manifestations.

Finally, it is quite likely that our patient had asymptomatic PAN, which will either remain as such, or will become manifest in the future. In such cases, clinicians should be aware of the possibility that a systemic necrotising vasculitis may, for some time, remain asymptomatic. Furthermore, mesenteric angiography, when used to help diagnose PAN in cases of multisystem clinical presentations, is not expected to disclose vasculitis when hepatic enzymes are normal, ${ }^{2}$ but even then the procedure may be of diagnostic help.

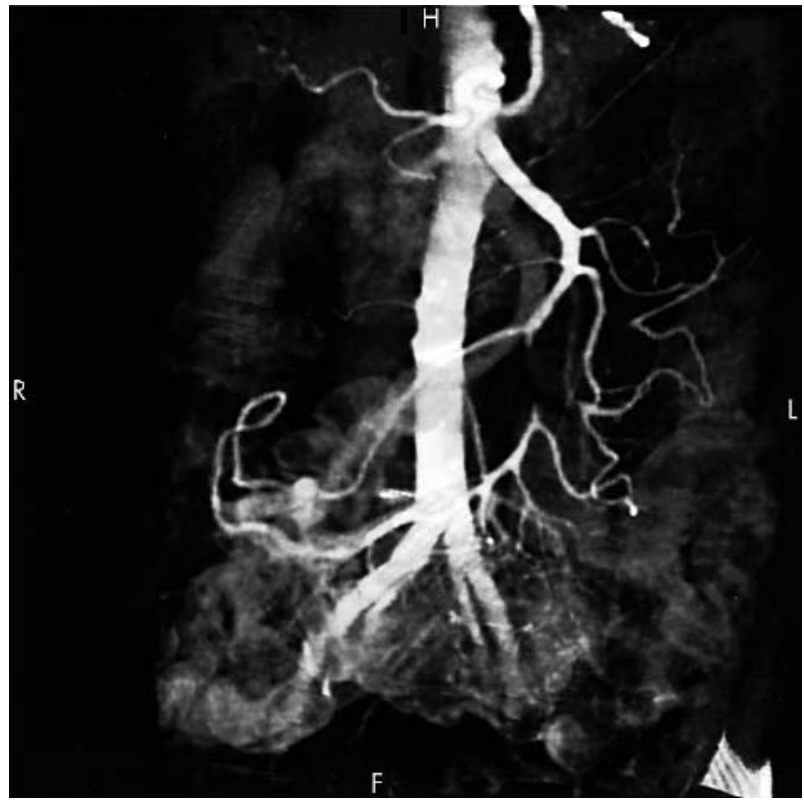

Figure 2 Multislice CT angiography of the abdomen. Obstruction of the superior mesenteric artery $6 \mathrm{~cm}$ after its origin and for $1.5 \mathrm{~cm}$ is noted, followed by reinfusion, supplemented by a large jejunal arterial branch, originating above the obstruction. Narrowing of the latter is seen at about its middle. Several jejunal branches of the superior mesenteric artery disclose stenoses at multiple sites, followed by mild dilatation (bead-like configuration). A small narrowing can be seen at the first portion of the right renal artery as well.

\section{Authors' affiliations}

A Bounas, G Giannopoulos, N Meimaris, A P Andonopoulos,

Department of Medicine, Division of Rheumatology, University of Patras School of Medicine, Patras, Greece

M Melachrinou, P Aroukatos, Department of Pathology, University of Patras School of Medicine, Patras, Greece

F Kalfarentzos, Department of Surgery, University of Patras School of Medicine, Patras, Greece

Correspondence to: Professor A P Andonopoulos, Internal Medicine and Rheumatology, University of Patras School of Medicine, 26500 Rio, Patras, Greece; andandon@med.upatras.gr

Accepted 28 April 2003

\section{REFERENCES}

1 Lhotte F, Guillevin L. Polyarteritis nodosa, microscopic polyangiitis, and Churg-Strauss syndrome: clinical aspects and treatment. Rheum Dis Clin North Am 1995;21:911-47.

2 Valente RM, Conn DL. Polyarteritis-polyarteritis nodosa and microscopic polyangiitis. In: Klippel JS, Dieppe PA, eds. Rheumatology. London: Mosby, 1998:7.20.1-10

3 Calabrese LH, Duna GF. Drug-induced vasculitis. Curr Opin Rheumatol 1996:8:34-40.

4 Merkel PA. Drugs associated with vasculitis. Curr Opin Rheumatol $1998 ; 10: 45-50$.

5 Choi HK, Merkel PA, Walker AM, Niles JL. Drug associated antineutrophil cytoplasmic antibody-positive vasculitis: prevalence among patients with high titers of antimyeloperoxidase antibodies. Arthritis Rheum 2000:43:405-13.

6 Merkel PA. Drug-induced vasculitis. Rheum Dis Clin North Am $2001 ; 27: 849-62$ 


\title{
Ultrasound detection of knee patellar enthesitis: a comparison with magnetic resonance imaging
}

\author{
M Kamel, $\mathrm{H}$ Eid, R Mansour
}

Ann Rheum Dis 2004;63:213-214. doi: 10.1136/ard.2003.010314

$\mathrm{T}$ he diagnosis of enthesitis in clinical practice is difficult and usually based on conventional radiographic findings, which are not helpful in most cases. ${ }^{1}$ We previously reported that ultrasound (US) was sensitive in detecting peculiar pathological features of enthesitis around the heel. ${ }^{2}$ Furthermore, we have continued to study the efficacy of ultrasonographic diagnosis of enthesitis of other tendon and ligament insertion sites.

\section{METHODS AND RESULTS}

Sixteen patients ( 10 male, six female, mean age 45.6 years) with a diagnosis of seronegative arthropathy were recruited from the population for the study. Their mean disease duration was 6.3 years. They had seronegative arthropathy and knee enthesopathy without typical conventional radiographic evidence. An HDI 3000 ATL US machine (Advanced Technology Laboratories, USA), equipped with a $12 \mathrm{MHz}$ linear transducer, was used to examine the knee patellar enthesis.

The present study produced interesting findings (figs IA and $\mathrm{B}$ ).The US images of the knee patellar enthesis showed loss of the normal fibrillar echo texture of the patellar tendon, no homogeneous pattern, blurring of the patellar tendon margins, irregular focal or generalised increased tendon thickness, and focal ill-defined tendon defects, with loss of their tightly packed echogenic dots. The US images clearly showed the definition of the patellar tendon margins, which were more precise and anatomically defined than the magnetic resonance (MR) images (figs $\mathrm{IC}$ and $\mathrm{D}$ ).

\section{DISCUSSION}

The US examination of the knee joint clearly detected the early calcification foci of the patellar tendons. However, the calcification process of the knee patellar ligament developed less often in the patients than the calcification of the Achilles tendon found in a previous report. ${ }^{2}{ }^{3}$

The process of fatty degeneration of the patellar tendon was detected early in US images, and appears as hyperechoic intratendinous lesions. ${ }^{4} 5$

This study detected a significant thickening of the patellar tendon, which can be measured by US. We believe that this US feature is more sensitive and reliable in diagnosing early enthesitis than a classical MR high signal intensity image
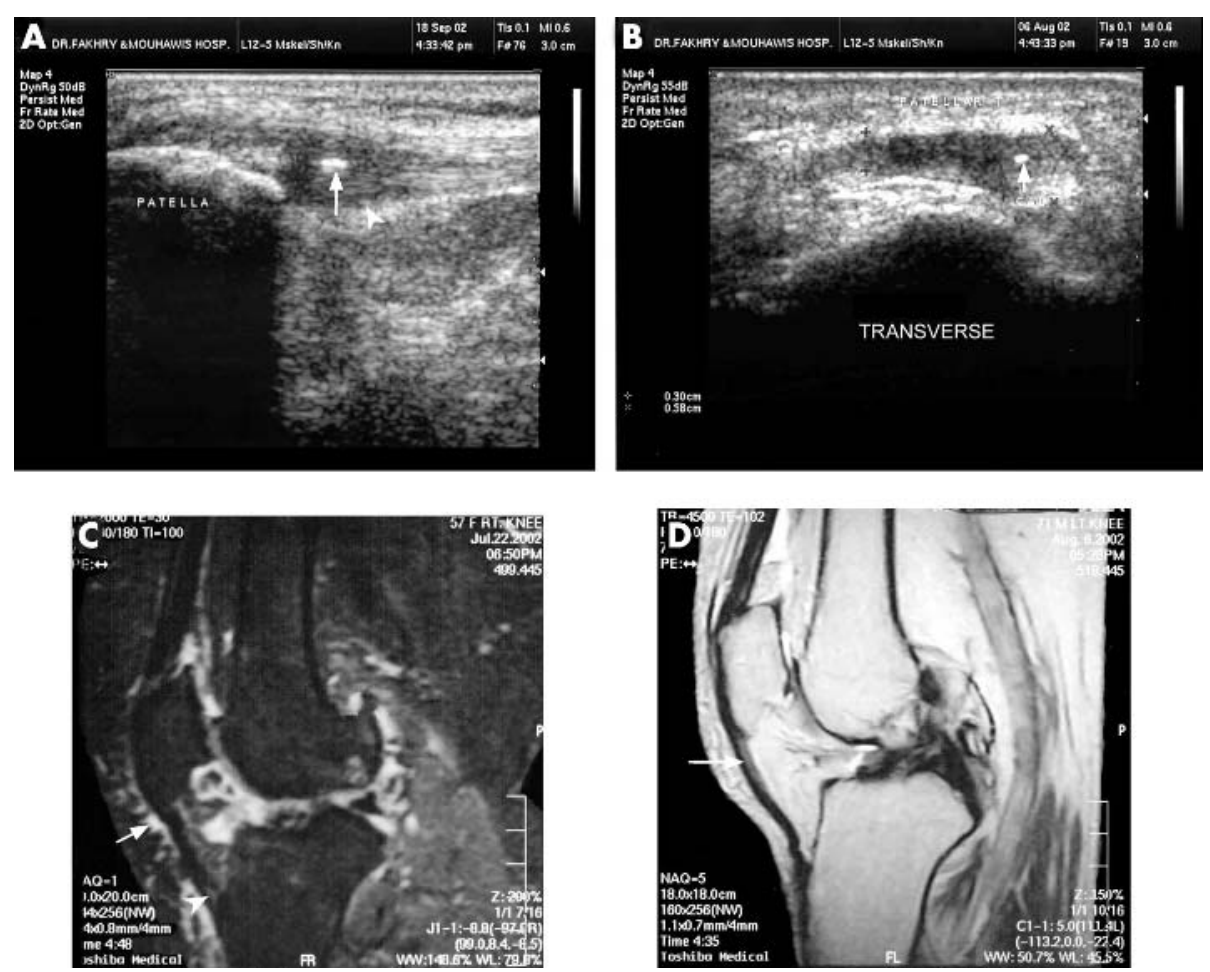

Figure 1 (A) A sagittal US scan shows thickened proximal entheses of the patellar ligament with loss of its fibrillar echo pattern, loss of the sharp definition of its posterior aspect compared with the distal portion (arrow head), calcific foci (arrow). (B) A transverse US scan of the same patient shows the thickened medial part of the patellar ligament with calcific focus (arrow). (C) A sagittal $\mathrm{T}_{2}$ fat suppression image shows the thickened distal part of the patellar tendon with altered signal intensity (arrow head) and prepatellar bursitis (arrow). (D) A sagittal Pd weighted image shows high intensity signals of the proximal patellar tendon. 
within the superior medial and central aspects of the patellar tendon at its proximal attachment. This interesting observation has been confirmed in other related studies. ${ }^{67}$

In conclusion, we found several pathological differences between the pattern of patellar enthesitis and that of Achilles tendon and plantar fascia of the heel. The entheseal changes of the patellar tendon occurred at the tibial or patellar insertion either on its medial or lateral aspect, but in the case of the Achilles tendon, the entheseal changes were detected only in the calcaneal insertion. The presences of Calcific foci were found more often in the Achilles tendon than in the patellar tendon. US is a valuable and sensitive diagnostic method in patients with seronegative spondyloarthropathy and knee enthesopathy who have normal findings with conventional radiological images of the knee joint.
R Mansour, Dr Fakhry and Almuhawis Hospital, Alkhobar, Saudi Arabia H Eid, Menofyia University, Egypt

Correspondence to: Dr M Kamel; mkamel56@hotmail.com

Accepted 28 April 2003

\section{REFERENCES}

1 Danda D, Shyam Kumar NK, Cherian R, Cherian AM. Enthesopathy: clinical recognition and significance. Nat Med J India Mar 2001;14:90-2.

2 Kamel M, Eid H, Mansour R. Ultrasonographic detection of enthesitis: a comparison with MRI. J Rheumatol 2003;30:774-8.

3 Kamel M, Moghazy K. Ultrasonographic detection of enthesitis: a comparison with MRI [abstract]. Arthritis Rheum 2001;44(suppl 9):95.

4 Rawool Nm, Nazarian LN. Ultrasound of the ankle and foot. Semin Ultrasound CT MR 2000;21:275-85.

5 Gibbon WW, Cooper JR, Radcliffe GS. Distribution of sonographically detected tendon abnormalities in patients with a clinical diagnosis of chronic achilles tendinosis. J Clin Ultrasound 2000;28:61-6.

6 Reiff DB, Heenan SD, Heron CW. MRI appearances of the asymptomatic patellar tendon on gradient echo imaging. Skeletal Radiol 1995;24:123-6.

7 Yu JS, Popp JE, Kaeding CC, Lucas J. Correlation of MR imaging and pathologic findings in athletes undergoing surgery for chronic patellar tendinitis. AJR Am J Roentgenol 1995;165:115-18.

\section{Authors' affiliations}

M Kamel, Al-Azhar University, Cairo, Egypt

\title{
Longlasting effects of immunoadsorption in severe Sjögren's syndrome
}

\author{
M Böhm, T Dörner, F Knebel, A Bruns, N Jochmann, G Baumann
}

$\mathrm{D}$ espite advances in understanding the immunopathogenesis of Sjögren's syndrome, successful therapeutic interventions are extremely limited.

\section{CASE REPORT}

With this in mind we began a immunoadsorption treatment of a 38 year old woman, diagnosed 1.5 years ago with Sjögren's syndrome. She reported dry eyes and mouth for several months and intermittent arthralgias, especially of the small finger joints and elbows, as well as swollen joints of the hands, elbows, and ankles for six years. During the six months before treatment her joint symptoms had increased significantly and considerably impaired everyday activities. A Schirmer's test was positive. The antinuclear antibodies and rheumatoid factor were raised, autoantibodies against Ro/SSA and La/SSB were positive. Thus, the patient fulfilled four of six revised criteria of primary Sjögren's syndrome. ${ }^{1}$

Previous corticoid treatment (prednisolone $20 \mathrm{mg}$ a day for four weeks) had led to oropharyngeal candida mycosis, and methotrexate ( $25 \mathrm{mg}$ a week) did not have a therapeutic effect. Because chloroquine had side effects in her family, the patient refused to take hydroxychloroquine. Upon presentation in our clinic, the patient took $5 \mathrm{mg}$ a day of prednisolone. Because the severe arthralgias and sicca symptoms did not respond to conventional treatment we started to treat the patient with immunoadsorption, to improve the symptoms by reducing IgG to $10-20 \%$ of its initial level.

Approval of the ethics committee and informed consent by the patient were obtained, and we started immunoadsorption therapy according to a previous protocol used for patients with dilated cardiomyopathy. ${ }^{23}$

Immunoadsorption treatment took place in two consecutive cycles with an interval of four weeks. The first cycle comprised three treatment days and the second, two. The plasma filtration was similar to haemodialysis. The IgGTherasorb Adsorber and a Mirosorb treatment unit
(Plasmaselect, Teterow, Germany) treated 7 litres plasma a day. Plasma IgG, antibody complexes, and fragments of antibodies were bound to the Fc fragment of polyclonal sheep antihuman antibodies, bound in turn to Sepharose. ${ }^{4}$

After the first treatment cycle, the patient showed remarkable clinical improvement, with lessening of arthalgias and articular swelling, and subsequent increased joint mobility. The score for tender/swollen joints ${ }^{5}$ reduced from a value of 29 at the beginning to 0 at the end of the study. Complement factors $\mathrm{C} 3$ and $\mathrm{C} 4$ fell to $67 \%$ and $78 \%$ of baseline $(0.8-0.6 \mathrm{~g} / \mathrm{l}$ and $0.19-0.15 \mathrm{~g} / \mathrm{l})$, respectively. In addition, circulating immune complexes reduced to $29 \%$ $(3.3-1.0 \mathrm{~g} / \mathrm{l})$ and the rheumatoid factor to $55 \%$ of initial value $(2.5-1.4 \mathrm{~g} / \mathrm{l})$. The treatment reduced IgG from 24.31 to $4.88 \mathrm{~g} / \mathrm{l}$ after the first cycle and from 22.72 to $10.04 \mathrm{~g} / \mathrm{l}$ after the second cycle. The IgG level increased within 16 months to $34.70 \mathrm{~g} / \mathrm{l}$.

The changes during the second treatment cycle were less striking in their effect on circulating immune complexes (reduced to $53 \%(1.55-0.83 \mathrm{~g} / \mathrm{l})$ ) and the rheumatoid factor (reduced to $92 \%$ of the initial level $(6.56-6.09 \mathrm{~g} / \mathrm{l})$ ). Increases were seen in the values of circulating immune complexes (from 0.83 to $0.96 \mathrm{~g} / \mathrm{l}$ ) and of rheumatoid factor (from 6.09 to $6.24 \mathrm{~g} / \mathrm{l})$ after 16 months.

As a result of the striking and sustained clinical benefit achieved, the treatment was discontinued after the second cycle of immunoadsorption.

\section{DISCUSSION}

To prevent a rebound and infection after immunoadsorption, the treatment protocol requires intravenous IgG substitution ( $0.5 \mathrm{~g}$ per kg body weight Venimmun) after each cycle, indicating that the patient's IgG has a significant role in the disease. We cannot exclude the possibility that immunoglobulin infusion may have had some effect on the outcome. This needs to be examined by additional studies. 
This case report suggests the potential advantages of immunoadsorption in severe Sjögren's syndrome which is refractory to conservative treatment. After 16 months the patient remains free of tender and swollen joints, and the sicca symptoms remain stable. A current open trial will provide further data, allowing better assessment of the value of immunoadsorption in patients with Sjögren's disease.

\section{Authors' affiliations}

M Böhm, F Knebel, N Jochmann, G Baumann, Department of Medicine, Cardiology, Angiology and Pneumology, Charité University Medical Centre, Berlin, Germany

T Dörner, A Bruns, Department of Medicine, Rheumatology and Clinical Immunology, Charité University Medical Centre, Berlin, Germany

Correspondence to: $\operatorname{Dr} M$ Böhm, Department of Medicine, Cardiology, Angiology, and Pneumology, University Hospital Charité, Schumannstr 20/21, D-10098 Berlin, Germany; marko.boehm@charite.de
Accepted 22 May 2003

\section{REFERENCES}

1 Vitali C, Bombardieri S, Jonsson R, Moutsopoulos HM, Alexander EL, Carsons SE, et al. Classification criteria for Siögren's syndrome: a revised version of the European criteria proposed by the American-European Consensus Group. Ann Rheum Dis 2002;61:554-8.

2 Felix S, Staudt A, Dörffel WV, Stangl V, Merkel K, Pohl M, et al. Hemodynamic effects of immunoadsorption and subsequent immunoglobulin substitution in dilated cardiomyopathy: three-month results from a randomized study. J Am Coll Cardiol 2000;35:1590-8.

3 Staudt A, Schaper F, Stangl V, Plagemann A, Böhm M, Merkel K, et al. Immunohistological changes in dilated cardiomyopathy induced by immunoadsorption therapy and subsequent immunoglobulin substitution. Circulation 2001;103:2681-6.

4 Koll RA. Prinzip und Leistung der Ig-Therasorb ${ }^{\circledR}$ - Immunadsorption. Klinische Immunadsorption 2000:23-25.

5 Felson DT, Anderson JJ, Boers M, Bombardier C, Furst D, Goldsmith C, et al. American College of Rheumatology. Preliminary definition of improvement in rheumatoid arthritis. Arthritis Rheum 1995;38:727-35.

\section{Juvenile temporal arteritis and activated protein $\mathrm{C}$ resistance}

\section{B Granel, J Serratrice, N Ene, P E Morange, P Disdier, P-J Weiller}

Ann Rheum Dis 2004;63:215-216. doi: 10.1136/ard.2003.008227

J uvenile temporal arteritis (JTA) is a rare benign vascular lesion limited to the branches of the external carotid artery, first recognised by Lie et al. ${ }^{1}$ Histological features of JTA include vasculitis (without giant cells and granulomas), lymphocytes infiltrate, and fibrous intimal proliferation. Despite frequent local arterial thrombosis associated with the lesion, no study on the coagulation pathway has been undertaken until now. We present an exceptional case of JTA occurring in a man in association with activated protein $\mathrm{C}$ resistance.

\section{CASE REPORT}

A 34 year old male smoker ( 12 cigarettes/day), without past medical history, consulted in January 2001 for right headache associated with swellings of both temples. Temporal regions were painful when he wanted to brush his hair. No visual or systemic symptoms occurred. Physical examination showed no pulse of the right temporal artery and a pulse of the left one; both arteries were thickened, tensed, indurated, and painful. Ultrasound echo Doppler disclosed arterial thrombosis of the right superficial temporal artery and normal aspect of the carotids and subclavicular arteries. Biological evaluation showed no inflammation (erythrocyte sedimentation rate $2 \mathrm{~mm} / \mathrm{lst} \mathrm{h}$ and $\mathrm{C}$ reactive protein $<4 \mathrm{mg} / \mathrm{l})$ and normal white blood cell count $\left(8 \times 10^{9} / \mathrm{l}\right.$, with $1.4 \%$ eosinophils), haemoglobin level, and platelet count. Histopathological analysis of the right temporal artery disclosed an inflammatory infiltrate with mononuclear cells without giant cells or granuloma, and a fibrous intimal proliferation. No eosinophils were seen in the biopsy. An electrocardiogram was normal. The patient was treated with aspirin $(100 \mathrm{mg} /$ day) and the temporal pain resolved. He stopped smoking.

Past familial history showed multiple phlebitides and a pulmonary embolism in the grandmother, a phlebitis in the mother, and three phlebitides in the father. Blood coagulation evaluation in the patient showed activated protein $\mathrm{C}$ resistance with heterozygous mutation in factor $\mathrm{V}$ gene (Arg 506-Gln). There was no mutation in factor II gene, normal levels of antithrombin, protein $S$, protein $C$, and protein Z, no lupus anticoagulant, and no anticardiolipin antibody. Homocystine level was normal. A search for antinuclear, antineutrophil cytoplasmic antibodies, and cryoglobulinaemia was negative. Funduscopic examination was normal. Angiographic magnetic resonance imaging of the cerebral arteries only performed a few months later (when the patient was referred to our medical department) was normal. Control of ultrasound echo Doppler performed 2 years later (when the patient was still receiving aspirin treatment) showed a persistent thrombosis of the right temporal artery associated with a myointimal thickness and a non-occlusive myointimal thickness of the left artery. Carotid, vertebral, and subclavicular arteries appeared to be normal. The patient continued to receive aspirin treatment.

\section{DISCUSSION}

JTA is a very rare entity of benign course and fewer than 15 cases have been reported. ${ }^{1-6}$ It is usually unilateral, although bilateral involvement, as seen in our case, has also been reported. ${ }^{6}$ JTA occurs in children or adults under 40 years, and is characterised by $(a)$ pain in the temporal region with arterial induration or palpable nodules; $(b)$ no associated inflammatory symptoms; (c) no objective ophthalmic symptoms; (d) no biological inflammation; (e) possible blood eosinophilia with eosinophilic infiltrate in biopsy; and $(f)$ no need for steroid treatment. The reported patients who were treated with steroids had systemic symptoms and an associated systemic vasculitis. ${ }^{3}$ More recently, rapid regression of the temporal pain in a patient with JTA treated with non-steroidal anti-inflammatory drugs has been reported. ${ }^{7}$

Differential diagnosis includes Kimura's disease (angiolymphoid proliferative disorder of soft tissues with eosinophilia and raised immunoglobulin E, occurring almost exclusively in oriental men), angiolymphoid hyperplasia with eosinophilia, ${ }^{8}$ giant cell arteritis, panarteritis nodosa, 
Takayasu's arteritis, and isolated vasculitis of the vasa vasorum. ${ }^{9}$ Histopathological analysis often discloses arterial thrombosis associated with non-giant cell, non-necrotising, and non-granulomatous vasculitis. A search for blood coagulation disorders has never been performed until now. Factor V Leiden is a well known risk factor for venous thrombosis but may also play a part in arterial thrombosis, particularly myocardial infarction ${ }^{10}$ or ischaemic cerebrovascular disease. ${ }^{11}$ Even if we cannot exclude a fortuitous association in our case, factor $\mathrm{V}$ Leiden mutation might have played a role in arterial thrombosis. This observation reminds doctors of this rare entity and highlights the need to study blood coagulation in cases of JTA.

\section{Authors' affiliations}

B Granel, J Serratrice, N Ene, P Disdier, P-J Weiller, Service de Médecine Interne, Hôpital de la Timone, 264 rue Saint Pierre, 13385 Marseille, cedex 5, France

P E Morange, Laboratoire d'Hématologie, Hôpital de la Timone, 264 rue Saint Pierre, 13385 Marseille, cedex 5, France

Correspondence to: Dr P Disdier; patrick.disdier@ap-hm.fr

Accepted 12 May 2003

\section{REFERENCES}

1 Lie JT, Gordon LP, Titus JL. Juvenile temporal arteritis. Biopsy study of four cases. JAMA 1975;234:496-9.

2 Villalta J, Estrach T. Temporal arteritis with normal erythrocyte sedimentation rate. Ann Intern Med 1985;103:808

3 Genereau T, Herson S, Piette JC, Coutellier A, Pelletier S, Wechsler B, et al. Temporal arteritis in young subjects. A trial of nosological classification on 6 cases. Ann Med Interne (Paris) 1992; 143:303-8.

4 Fielding DI, Brown IG. Temporal arteritis in a young patient with a normal erythrocyte sedimentation rate. Aust NZ J Med 1994;24:66-7.

5 Tomlinson FH, Lie JT, Nienhuis BJ, Konzen KM, Groover RV. Juvenile temporal arteritis revisited. Mayo Clin Proc 1994;69:445-7.

6 Lie JT. Bilateral juvenile temporal arteritis. J Rheumatol 1995;22:774-6.

7 Carreiro M, Margarit-Coll N, Oksman A, Dahan S, Ollier S, Sailler L, et al. Juvenile temporal arteritis: a benign disease. Rev Med Interne 2003;24:138-9.

8 Olsen TG, Heing EB. Angiolymphoid hyperplasia with eosinophilia: a clinicopathologic study of 116 patients. J Am Acad Dermatol 1985;12:781-96.

9 Disdier P, Pellissier JF, Harle JR, Figarella-Branger D, Bolla G, Weiller PJ. Significance of isolated vasculitis of the vasa vasorum on temporal artery biopsy. J Rheumatol 1994;21:258-60.

10 Doggen CJ, Cats VM, Bertina RM, Rosendaal FR. Interaction of coagulation defects and cardiovascular risk factors: increased risk of myocardial infarction associated with factor $V$ Leiden or prothrombin 20210A. Circulation 1998;97:1037-41.

11 De Lucia D, Nina P, Papa ML, Belli A, Conte M, Renis V, et al. Activated protein $\mathrm{C}$ resistance due to a factor $\mathrm{V}$ mutation associated with familial ischemic stroke. J Neurosurg Sci 1997;41:373-8.

\section{Serum osteoprotegerin but not receptor activator of NF- $\kappa B$ ligand correlates with Larsen score in rheumatoid arthritis}

\section{Skoumal, G Kolarz, W Woloszczuk, G Hawa, A Klingler}

O steoprotegerin (OPG) is a soluble decoy receptor, produced by osteoblastic cells and in the inflamed synovium of RA by dendritic cells, B cells, and other immunocompetent cells. ${ }^{12}$ It inhibits the differentiation of osteoclast precursor cells and the activation of mature osteoclasts by neutralising the receptor activator of NF- $\mathrm{KB}$ ligand (RANKL). ${ }^{3}$

RANKL, a member of the tumour necrosis factor family, is expressed on prae-osteoblasts and T lymphocytes. A soluble RANKL (sRANKL) can be produced by activated T lymphocytes or can be generated from the cell bound form by a protease. RANKL itself activates a receptor activator of NF- $\mathrm{\kappa B}$ (RANK). ${ }^{4}$

RANKL, together with monocyte-colony stimulating factor, interleukin 1 , and RANK is responsible for osteoclast formation and activation and inhibits osteoclast apoptosis. Thus OPG acts as antagonist to RANKL. An imbalance of this system may play a part in the skeletal complications of rheumatoid arthritis (RA). ${ }^{5}$

Our study aimed at comparing OPG and sRANKL in the serum of patients with RA.

We identified 44 patients with RA (24 female, 20 male, mean age at manifestation of RA 49 years) with 60 measurements. Sixteen patients received low dose steroids, five patients showed generalised osteoporosis ( $x$ ray and/or osteodensitometry).

The results were analysed by Spearman correlation statistics and Wilcoxon two sample test.

Serum OPG levels were measured in patients with RA using a sandwich-type enzyme linked immunosorbent assay

Table 1 Correlation of OPG and sRANKL with clinical data

\begin{tabular}{|c|c|c|c|c|c|c|c|}
\hline \multirow[b]{2}{*}{ Clinical data } & \multirow[b]{2}{*}{ Mean } & \multirow[b]{2}{*}{ SD } & \multirow[b]{2}{*}{ No } & \multicolumn{2}{|l|}{ OPG } & \multicolumn{2}{|c|}{ sRANKL } \\
\hline & & & & $r_{\mathrm{s}}$ & p Value & $r_{\mathrm{s}}$ & p Value \\
\hline sRANKL (pmol/I) & 0.90 & 0.85 & 60 & 0.21 & 0.10 & & \\
\hline $\operatorname{ESR}(\mathrm{mm} / 1 \mathrm{st} \mathrm{h})$ & 37.3 & 24.2 & 60 & 0.29 & 0.03 & 0.004 & 0.77 \\
\hline CRP $(\mathrm{mg} / \mathrm{l})$ & 38.2 & 30.5 & 60 & 0.15 & 0.24 & 0.09 & 0.49 \\
\hline $\mathrm{RF}(\mathrm{U} / \mathrm{I})$ & 418.5 & 1584.8 & 60 & 0.02 & 0.90 & 0.05 & 0.71 \\
\hline DAS & 3.44 & 1.09 & 60 & 0.21 & 0.11 & 0.02 & 0.86 \\
\hline Larsen score & 49.7 & 44.7 & 60 & 0.32 & 0.01 & -0.02 & 0.85 \\
\hline
\end{tabular}

OPG, osteoprotegerin, sRANKL, soluble receptor activator of NF- $\mathrm{KB}$ ligand; ESR, erythrocyte sedimentation rate, $\mathrm{CRP}, \mathrm{C}$ reactive protein; RF, rheumatoid factor; DAS, disease activity score. 
(ELISA) based on two OPG-specific antibody preparations. The mean value of a healthy control group of 170 blood donors $^{6}$ is $2.2 \mathrm{pmol} / \mathrm{l}$ (2.0 pmol/l for men, $2.4 \mathrm{pmol} / \mathrm{l}$ for women).

sRANKL was measured by an enzyme catalysed colour change detectable on a standard ELISA reader. To measure only the biologically active form(s) of sRANKL biosynthetic OPG/Fc was used as capture protein. The mean value of serum sRANKL levels in healthy subjects was calculated as $1.3 \mathrm{pmol} / \mathrm{l}$ (median 0.9).

We detected serum levels of OPG with a mean value of $4.2 \mathrm{pmol} / \mathrm{l}$ (SD 2.0) and serum levels of RANKL with a mean value of $0.9 \mathrm{pmol} / \mathrm{l}$ (SD 0.8). We found a significant correlation between OPG and erythrocyte sedimentation rate (ESR) and OPG and the Larsen score but no correlation between RANKL and OPG or between RANKL and the clinical and radiological measures (table 1).

No significantly different OPG levels were found either in patients receiving steroids or in patients with osteoporosis.

In RA RANKL leads to bone erosions by activation of osteoclasts, and this process is inhibited by OPG. ${ }^{7}$ Therefore OPG seems to play an important part in preventing erosions and osteoporosis in patients with RA. Kolarz et al suggested that patients with active inflammation may show higher OPG values owing to activation of several other cells. ${ }^{8}$ Haynes et al showed an increased expression of RANKL in tissues surrounding bone erosions and at the same time OPG was absent in tissues from patients with active RA. ${ }^{9}$

Despite the presence of raised serum OPG levels acting as protection mechanism, the local destructive effect of RANKL by activation of osteoclasts seems not to be fully balanced.

The up regulation of OPG might be a response to the inflammation; in contrast an up regulation of RANKL could not be found in the serum of patients with RA.

Haynes et al reported that OPG and RANKL behave differently depending on the cells which produce them. ${ }^{10} \mathrm{~A}$ further explanation may be the different strategies of both assays: the OPG assay measures free and bound OPG, the sRANKL assay only free sRANKL; complexes formed from OPG and sRANKL would therefore be detected only with the OPG, but not with the sRANKL assay.

\section{Authors' affiliations}

M Skoumal, G Kolarz, Institut für Rheumatologie der Kurstadt Baden in Kooperation mit der Donauuniversität Krems, Rheumasonderkrankenanstalt der SVA der gewerblichen Wirtschaft, Baden, Austria W Woloszczuk, Ludwig Boltzmann Institut für experimentelle Endokrinologie, Vienna, Austria

G Hawa, Biomedica Medizinprodukte GmbH \& Co KG, Austria A Klingler, Theoretical Surgery Unit, Department of General and Transplant Surgery, University Hospital, Innsbruck, Austria

Correspondence to: Dr M Skoumal, Rheumasonderkrankenanstalt der SVA der gewerblichen Wirtschaft, Adolfine Malchergasse 1, 2500 Baden, Austria; martin.skoumal@al.net

Accepted 28 April 2003

\section{REFERENCES}

1 Simonet WS, Lacey DL, Dunstan CR, Kelley M, Chang MS, Luthy R, et al. Osteoprotegerin: A novel secreted protein involved in the regulation of bone density. Cell 1997:89:309-19.

2 Itonaga I, Fujikawa Y, Sabokar A, Murray DW, Athanasou NA. Rheumatoid arthritis synovial macrophage-osteoclast differentiation is osteoprotegerin ligand-dependent. J Pathol 2000;192:97-104.

3 Burgess TL, Qian Y, Kaufman S, Ring BD, Van G, Capparelli C, et al. The ligand for osteoprotegerin (OPGL) directly activates mature osteoclasts. J Cell Biol 1999; 145:527-38.

4 Hofbauer LC, Heufelder AC. Role of receptor activator of nuclear factor $-\kappa B$ ligand and osteoprotegerin in bone cell biology. J Mol Med 2001:79:243-53

5 Takayanagi $\mathrm{H}$, lizuka H, Juji T, Nakagawa T, Yamamoto A, Miyazaki T, et al. Involvement of receptor activator of nuclear factor- $\kappa B$ ligand osteoclast differentiation factor in osteoclastogenesis from synoviocytes in rheumatoid arthritis. Arthritis Rheum 2000:43:259-69.

6 Kudlacek S, Schneider B, Woloszczuk W, Pietschmann P, Willvonseder R. Serum levels of osteoprotegerin increase with age in healthy adult population. Bone 2003;32:681-6.

7 Gravallese EM, Manning C, Tsay A, et al. Synovial tissue in rheumatoid arthritis is a source of osteoclast differentiation factor. Arthritis Rheum 2000;43:250-8

8 Kolarz G, Schödl CH, Skoumal M, Woloszczuk W, Wottawa A Osteoprotegerin serum levels in rheumatoid arthritis: J Mineralstoffwechsel, (in press).

9 Haynes DR, Crotti TN, Loric M, Bain GI, Atkins GJ, Findlay DM. Osteoprotegerin and receptor activator of nuclear factor- $\kappa B$ ligand (RANKL) regulate osteoclast formation by cells in the human rheumatoid arthritic joint. Rheumatology (Oxford) 2001:40:623-30.

10 Haynes DR, Barg E, Crotti TN, Holding C, Weedon H, Atkins GJ, et al. Osteoprotegerin expression in synovial tissue from patients with rheumatoid arthritis, spondylarthropathies and osteoarthritis and normal controls. 2003;42: 123-34

\section{Successful management of neonatal cryoglobulinaemia after a gemellar pregnancy in a woman with symptomatic type I cryoglobulinaemia}

\section{J Sibilia, O Feugeas, V Laugel, A Dreval, J Messer, J Goetz}

\section{CASE REPORT}

Since 1996 a 32 year old woman had had cold-induced clinical manifestations: Raynaud's phenomenon, livedo reticularis, necrotic and purpuric lesions on the legs, and acrocyanosis on the ears and fingers. She had no family history of cold intolerance, autoimmune disease, or recurrent thrombosis. In 1998 these symptoms were traced to a monoclonal IgGl $\lambda$ cryoglobulin (type I) present at $1.5 \mathrm{~g} / \mathrm{l}$ and precipitating at $27^{\circ} \mathrm{C}$. Cold agglutinin and cryofibrinogen were absent while total complement $\left(\mathrm{CH}_{50}\right)$ and $\mathrm{C} 4$ fraction were low. There were no antinuclear, anti-dsDNA, antineutrophil, anticardiolipin, or anti- $\beta 2$-glycoprotein I antibodies, and viral serology was negative for hepatitis $\mathrm{B}$ and $\mathrm{C}$ and cytomegalovirus. A skin biopsy showed leucocytoclastic vasculitis and thrombosis of the capillaries related to the cryoglobulin. There were no renal, gastrointestinal, or neurological manifestations, but the patient had intermittent distal polyarthritis and was treated with pentoxifylline accompanied by protective measures against cold.

This mother had born a first healthy child in 1996 and had experienced no previous miscarriage. In 2000, during a second dichorionic gestation of twins, the lesions were progressive while the cryoglobulin persisted at $1.10 \mathrm{~g} / \mathrm{l}$. Because the $\operatorname{IgGl} \lambda$ chain can cross the placenta and the initial temperature of cryoprecipitation was $27^{\circ} \mathrm{C}$, clinical manifestations could be expected in the newborns at room 


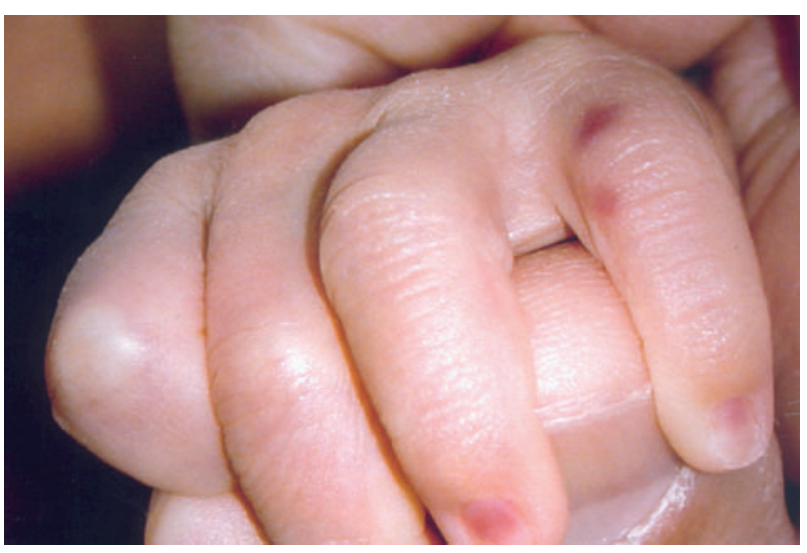

Figure 1 Cyanotic lesions of the boy's fifth finger after exposure to room temperature

temperature. Treatment of the mother consisted only of protection against cold. Plasmaphereses were not performed as these do not totally eliminate cryoglobulin and have potential drawbacks, such as inducing premature labour by altering the plasma volume or hormone levels, or decreasing fetal nutrients and maternal and fetal serum immunoglobulin levels. General measures were defined to avoid cryoprecipitation at delivery: a room at $28^{\circ} \mathrm{C}$, adapted clothes permitting medical supervision, warming of liquids to $37^{\circ} \mathrm{C}$ before perfusion to the mother, and placing the newborns in incubators.

The twins (female and male weighing $2440 \mathrm{~g}$ and $2690 \mathrm{~g}$, respectively) were delivered after 39 weeks' gestation and immediately put in incubators at $32^{\circ} \mathrm{C}$. One and five minute Apgar scores were 10 for both neonates, and no cutaneous or visceral involvement was detected, despite the presence of cryoglobulin at $1.70 \mathrm{~g} / \mathrm{l}$ in cord blood. Two days later the twins were placed in a room at $25^{\circ} \mathrm{C}$, but after 3 hours small erythrocyanotic maculae appeared on the boy's fifth finger (left hand) (fig l) and second and fourth toes (left foot). These lesions were very similar to those seen in the mother, whereas careful examination of the girl disclosed no cutaneous manifestations. The twins were replaced in incubators and the lesions disappeared slowly within one week.

After another 2 days they were removed from the incubators and dressed warmly, no further lesions were observed and the dressing precautions could be gradually abandoned before discharge. The monoclonal IgG1 $\lambda$ cryoglobulin was detected in the serum of both neonates at comparable levels, but it was unfortunately not possible to obtain follow up of these results. Six months later the twins were healthy while the mother's status remained stable with an unchanged serum cryoglobulin ( $1 \mathrm{~g} / \mathrm{l}$ ).

\section{DISCUSSION}

Maternal IgGs can cross the placenta, as is well illustrated by certain neonatal autoimmune diseases related to maternal autoantibodies. ${ }^{1}$ In the present case a monoclonal IgGl cryoglobulin identified in the mother and her twin children was associated with transient cold-induced lesions in one child. ${ }^{2-4}$ This is the first report of a pathogenic neonatal effect due to the transplacental passage of a type I cryoglobulin. Although the lesions were probably favoured by the high precipitation temperature $\left(27^{\circ} \mathrm{C}\right)$, many other physicochemical parameters can influence cryoprecipitation and hence might explain the difference between the two twins. Progressive clearance of the maternal IgGl after its passive transfer may further explain the favourable outcome and absence of recurrence. Such cases are rare, probably on account of the low incidence of type I cryoglobulinaemia in women of child bearing age. ${ }^{5}$ Associations between pregnancy and other types of cryoglobulin have been described but without related neonatal lesions. ${ }^{67}$ In a patient with mixed type II cryoglobulin and hepatitis C infection, cryoglobulinaemia was responsible for placental lesions inducing pre-eclampsia, but no specific neonatal lesions were seen. $^{8}$

The consequences for the fetus of the transplacental passage of IgG type I cryoglobulin are still unknown and the management of such pregnancies is difficult owing to the lack of a consensual procedure for the prevention of maternofetal complications. Corticosteroids or immunosuppressive drugs have failed to demonstrate any benefit. In our experience, protection against cold seems to be the only way to avoid precipitation of the cryoglobulin in the vessels of the mother and neonates with its pathogenic effects.

\section{Authors' affiliations}

J Sibilia, O Feugeas, V Laugel, A Dreval, J Messer, J Goetz, University of Strasbourg, France

Correspondence to: Professor J Sibilia, University Hospital of Strasbourg, avenue Molière Strasbourg, 67098 France; jean.sibilia@wanadoo.fr

Accepted 11 November 2003

\section{REFERENCES}

1 Buyon JP, Kim MY, Copel JA, Friedman DM. Anti-Ro/SSA antibodies and congenital heart block: necessary but not sufficient. Arthritis Rheum 2001;44:1723-7.

2 Brouet JC, Clauvel JP, Danon F, Klein M, Seligmann M. Biological and clinical significance of cryoglobulins. Am J Med 1974;57:775-88.

3 den Hollander JG, Swaak AJG. Essential cryoglobulinaemia (type 1) in three patients characterised by Raunaud's phenomenon, arthralgia-arthritis, and skin lesions. Ann Rheum Dis 2002;61:88-9.

4 Cohen SJ, Pittelkow MR, Su WP. Cutaneous manifestations of cryoglobulinemia: clinical and histopathologic study of seventy-two patients. J Am Acad Dermatol 1991;25:21-7.

5 Dispenzieri A, Gorevic PD. Cryoglobulinemia. Hematol Oncol Clin North Am 1999; 13:1315-49

6 Goodman GJ, Ryan PF, Sinclair RA. Post-partum nephrotic syndrome in mixed essential cryoglobulinemia. Aust N Z J Med 1983;13:633-5.

7 Whiting DA. Systemic lupus erythematosus with cryoglobulinaemia, peripheral gangrene, and transplacental passage of the LE factor: a case report. S Afr Med J 1967;13:479-82.

8 Alberico S, Mazza S, Grimaldi E, Volpe C, Cuaschino S. Essential mixed type II cryoglobulinemia in a HCV positive pregnant woman: a case report. Clin Exp Obstet Gynecol 1998;25:129-31. 


\section{Primary Raynaud's phenomenon in monozygotic twins T Oskay, Ü Ölmez}

W report two cases of primary Raynaud's phenomenon in 16 year old monozygotic female twins.

\section{CASE REPORT}

The twins were admitted to the dermatology department with a one year history of the sudden onset of episodic purple lesions on both hands. Presentation of the lesions in the twins was synchronous. After careful questioning, we determined that it was usually induced by emotion or cold temperature. On dermatological examination, the order of purple discolouration, erythema, and pallor was observed symmetrically in both hands. There was no history of smoking, the use of drugs, occupational hazard, or trauma. They also had sensations of coolness and paraesthesia. Photographs of the hands were obtained during an attack and used to confirm the history. We also performed a provocative test-namely, immersion of the patient's hand in ice water for three minutes, to confirm the diagnosis. Nailfold capillaroscopy examination also demonstrated normal capillaries. The female twins were born at 38 weeks of gestation by caesarean section. Obstetric anamnesis was normal. The twins' past medical history was unremarkable. Their parents were relatives, but the family history was negative for cutaneous or collagen vascular disease.

Results of laboratory examinations, including complete blood count, biochemistry, urine analysis, thyroid function tests, serum cryoglobulins, complement levels, immunoglobulins, erythrocyte sedimentation rate, and $\mathrm{C}$ reactive protein, were normal. Serological testing for antinuclear antibody, anticardiolipin antibodies, and antibody to Ro, La, dsDNA, ribonucleoprotein, and Smith antigen were negative. The twins were diagnosed as monozygotic with almost complete certainty by examining the ABO blood type, HLA typing, fingerprints, and from the physical resemblance between them. Identical HLA antigens were HLA-A2, A24, B17, B57, Cw3, Cw6, DR4, and DR11. Medical evaluation subsequently disclosed no disorder known to cause secondary Raynaud's phenomenon (RP).

\section{DISCUSSION}

$\mathrm{RP}$ is an exaggerated vascular response to cold temperature or emotional stress, primarily seen in young women. It is classified into primary or idiopathic without underlying disease and secondary when it is related to various medical problems. ${ }^{12}$ Clinical criteria are used to distinguish between patients with uncomplicated or primary RP, and those with secondary RP. The suggested criteria for primary RP are symmetric attacks; the absence of tissue necrosis, ulceration or gangrene; the absence of a secondary cause on the basis of a patient's history and general physical examination; normal nailfold capillaries; a negative test for antinuclear antibody; and a normal erythrocyte sedimentation rate. ${ }^{23}$ The most common diseases associated with secondary RP are scleroderma, mixed connective tissue disease, systemic lupus erythematosus, occlusive vascular disease, drug effects, haematological abnormalities, and use of vibrating tools. ${ }^{1{ }^{3}}$
Primary RP occasionally evolves into a connective tissue disease, most commonly scleroderma. ${ }^{24}$

Even though the cause of primary RP is not known, increased $\alpha 2$ sympathetic receptor activity on vessels, endothelial dysfunction, deficiency of calcitonin gene related peptide, protein-containing nerves, or some central thermoregulatory defect have been implicated. ${ }^{4}$ A genetic cause for primary RP was first suggested by Lewis and Pickering, based on an apparent familial aggregation of primary RP. ${ }^{78}$ MacGregor et al first assessed the genetic basis of RP in a population based twin study and found a substantial genetic contribution to the symptoms of RP. ${ }^{9}$ Recently, three potential candidate genes have been described in the genetic susceptibility to primary RP. ${ }^{10}$

To the best of our knowledge, this is the first report documenting the occurrence of primary RP in monozygotic twins. Association with HLA antigens, parental consanguinity, and development in identical twins may indicate that genetic factors have a role in the occurrence of this disease. Larger series of twins and investigation of multicase families are needed to clarify the genetic component in the pathogenesis of primary RP.

\section{ACKNOWLEDGEMENT}

We thank Omer Edip Erdemli MD, for his assistance in patient care.

\section{Authors' affiliations}

T Oskay, Department of Dermatology Bayındır Medical Centre Ankara, Turkey

Ü Ölmez, Department of Clinical Immunology and Rheumatology, Ankara University Faculty of Medicine Ankara, Turkey

Correspondence to: Dr T Oskay, Mesa Park Sitesi Sedir Apt, Daire: 44 06400 Oran, Ankara, Turkey; tubaoskay@hotmail.com

Accepted 27 March 2003

\section{REFERENCES}

1 LeRoy EC, Medsger TA Jr. Raynaud's phenomenon: a proposal for classification. Clin Exp Rheumatol 1992;10:485-8.

2 Wigley FM. Raynaud's phenomenon. N Engl J Med 2002;347:1001-8.

3 Turton EP, Kent PJ, Kester RC. The aetiology of Raynaud's phenomenon. Cardiovasc Surg 1998;6:431-40.

4 Bunker CB, Goldsmith PC, Leslie TA, Hayes N, Foreman JC, Dowd PM Calcitonin gene-related peptide, endothelin-1, the cutaneous microvasculature and Raynaud's phenomenon. Br J Dermatol 1996;134:399-406.

5 Ho M Belch JJ. Raynaud's phenomenon: state of the art. 1998. Scand J Rheumatol 1998;27:319

6 Freedman RR, Mayes MD. Familial aggregation of primary Raynaud's disease. Arthritis Rheum 1996;39:1189-91.

7 Tan FK, Arnett FC. Genetic factors in the etiology of systemic sclerosis and raynaud's phenomenon. Curr Opin Rheumatol 2000;12:511-19.

8 Bunker CB, Atherton D, Gray OP, Tsioupra K, Delhanty JDA, Dowd PM. Familial Raynaud's phenomenon and localized scleroderma associated with essential telangiectasia and cytogenetic abnormalities. J R Soc Med 1990;83:531-2.

9 MacGregor AJ, Cherkas LK, Carter L, Black M, Spector TD. The genetic contribution to Raynaud's phenomenon: a population-based twin study [abstract]. Arthritis Rheum 1999;42(suppl):S233.

10 Susol E, MacGregor AJ, Barrett JH, Wilson H, Black C, Welsh K, et al. A two stage genome-wide screen for susceptibility loci in primary Raynaud's phenomenon. Arthritis Rheum 2000;43:1641-6. 